\title{
REVISIONES
}

\section{Saber campesino: otra forma de experimentar la escuela rural}

\author{
Peasant knowledge: another way to experience rural school \\ Saber camponês: outra forma de experienciar a escola do campo
}

\author{
Sylvia Contreras Salinas \\ Universidad, Complutense de Madrid, Departamento de Teoría e Historia de la Educación, nemesis.syl@ \\ gmail.com, (034) 918449159
}

\begin{abstract}
RESUMEN
En el marco de la diversidad sociocultural no basta con saber que existen otras formas de vivir la vida u otras cosmovisiones, por el contrario, es necesario situarse dentro de un nuevo marco que debe generarse en un diálogo de sujetos epistémicos/as que constituyen distintos mundos y que necesitan interconectarse para refundar una educación intercultural. En este contexto, la presente reflexión intentará dar cuenta de algunos saberes, con el objeto de intensificar dicho diálogo, constituyéndose en una invitación a cruzar la frontera de los paradigmas que definen nuestros actuales proyectos educativos. El ensayo se nutre de los saberes de un campesino de la zona central de Chile, quien nos habla de su vida y sobre la educación. Como conclusión se desprende la demanda de una educación para la vida, construida en base a los saberes, la historia y la vida cotidiana de los seres humanos que se sumergen en su contexto local.
\end{abstract}

Palabras clave: saber, educación, decolonialidad, interculturalidad.

\begin{abstract}
In the context of socio-cultural diversity is not enough to know that there are other ways of living life or other world views; on the contrary, it's necessary to establish a position from a new framework generated in the dialogue of epistemological individuals representing different worlds and who are under the need of interconnecting themselves in order to reform intercultural education. In this context, this discussion will attempt to account some theoretical knowledge, in order to intensify this dialogue turning into an invitation to cross the border of the paradigms that define our current educational projects. This essay draws on the knowledge of a farmer from central Chile, who talks about his life and education. In conclusion, it appears the demand for an education for life, built on knowledge, history and daily life of human beings who are immersed in their local contexts.
\end{abstract}

Key words: knowledge, education, decoloniality, interculturalism.

\section{RESUMO}

No contexto da diversidade socio não é suficiente reconhecer que há outros modos de vida ou outras cosmovisões. Ao contrário, é preciso situar-se dentro de um novo marco capaz de produzir diálogos entre sujeitos epistêrmicos que constituem e são constiuídos em diferentes mundos e que necessitam interconectar-se para fundamentar uma educação intercultural. Neste contexto, constitue-se uma tentativa de dar conta de alguns saberes, objetivando intensificar o respectivo diálogo. Constite-se um convite para cruzar a fronteira dos paradigmas que definem nossos atuais projetos educacionais. Baseia-se em saberes de um camponês da zona central do Chile ao narrar sua vida e educação. Conclui-se que a demanda de uma educação para a vida, baseada nos saberes, na história e na vida cotidiana de pessoas subimersas em seu contexto local.

Palavras chave: saber, educação, descolonialidade, interculturalidade. 


\section{INTRODUCCIÓN}

Este ensayo recogerá ideas de grandes pensadores, no con el fin de analizar ni criticar importantes teorías ni a sus mayores exponentes, de eso ya hay bastante, sino para algo más osado: intentar mostrar el saber, el pensar y el actuar de un hombre que se levanta temprano cada día y sale a trabajar la tierra de otro, que vuelve cuando el sol se esconde con las manos agrietadas. Un hombre que vive en y con sus deidades, sus hierbas y su espíritu fuerte. Una voz silenciada que puede y tiene la legitimidad de ser referente y propuesta de pensamiento, así como de interpelar la educación moderna.

Es éste un ejercicio que responde a las demandas de una ciudadanía intercultural, por tanto de una educación que educa desde la interculturalidad, en la interculturalidad y con interculturalidad (Hopenhayn, 2009), de la condición humana de pluralidad y su aparecer en el otro/a (Arendt, 1993) y de una práctica de decolonialidad de lo campesino en sociedades que se dicen democráticas e interculturales (Lander, 2000; Mignolo 2007; Dussel 2002), intentando constituir una acción de diálogo en la diferencia. Diferencia situada tanto en su especificidad, como en su capacidad de proporcionar elementos para establecer críticamente relaciones sociales y prácticas culturales (Rengifo, 2003).

En este ensayo se reflexiona dialogando con Juan y con su historia plasmada en su discurso. Nuestros discursos y algunos hilos de otros discursos irán conformando un corpus en que destacará la fuerza simbólica intrínseca y la capacidad de conexión y de canalización de tensiones y luchas cotidianas del discurso de Juan.

Como bien lo indica Arendt, la historia narrada de Juan ${ }^{1}$ es la consecuencia de su inmersión en el mundo de los seres humanos. Él inicia y protagoniza la historia, es su actor y paciente, pero ella está formada de y en una trama de relaciones donde los seres humanos actúan y hablan unos/as para otros/as y otros/as para unos/as (1993). En palabras de Iñiguez, esto no sería un conjunto de meras expresiones sino más bien constituirían prácticas sociales, formas de interacción social con sus propios objetivos, preocupaciones, problemas y estrategias para producir sentido y variables en función del contexto (Iñiguez, 2006).

Nuestra pretensión es hacer un aporte al ejercicio que algunos/as estamos obstinados/ as en realizar: la acción de buscar, escuchar y re-encontrar seres humanos que hablen un lenguaje que no recurra a la lengua hegemónica que se ha instalado en el largo proceso de colonialidad (De Sousa Santos, 2003; Walsh 2007; Bowers 2002, entre otros/as).

\section{EL DISCURSO DESDE LO COTIDIANO}

Al reflexionar surge la idea que la educación debe dar la oportunidad de dejarse tocar con otras palabras, otros gestos y, al mismo tiempo, hacer brillar estas otras formas de vivir la vida, para que pueda ejercer su verdadero rol y no se quede estancada en dogmas muertos como lo denuncia Chomsky (2001). Consideramos que aprender a expresar

\footnotetext{
1 Discurso que se constituye a partir de una conversación informada y autorizada con Juan: campesino de un sector de Paine en diciembre del 2009 mientras componía los huesos de la mano de un familiar.
} 
nuestra propia palabra es un gran paso; lo ideal es que ést, al unirse con la palabra de otros/as, haga de la escuela un espacio diverso con miles de posibilidades y sentidos.

Don Juan, un campesino de la zona rural de la región central de Chile, se constituye en el contacto con la tierra, espacio que se propone como experiencia que se amplía y trasciende los límites de lo individual. Una experiencia que se puede y debe re-crear dentro en la escuela rural, para que las institución educativa sean realmente un espacio de vida, de diálogo y de crianza que es parte del espíritu que brota de la propia experiencia vital (Yampara, 2006; Rengifo, 2009), en donde no se separe el aprender del vivir (Rengifo 2003), en donde los encuentros de persona a persona sean el hilo conductor del trabajo diario, que permita sentirse parte de una gran comunidad y de una vida que merece la pena ser vivida desde lo que sé es; que supere la soledad construida sobre ruinas (saberes olvidados, bosques exterminados, tierras usurpadas, migraciones y desarraigos) una vida que se viva sin prisas, en un entorno cuyas historias se originan en infancias pobres.

Pensamos que, en su hablar y el de muchos/as más, entrega pistas a la educación para ser una expresión de vida buena, de hospitalidad y de responsabilidad (Bárcena y Mélich, 2000; Levinas, 1991), de saber de sí mismo/a, de sus raíces y del establecimiento de parámetros de lo que cada uno y una es y de los que son los/as otros/ y su entorno, su espacio y su tiempo. Una educación que atañe a todos y todas en cualquier lugar, rescatando para las nuevas generaciones las distintas maneras de saber y de estar en este mundo (Feyeranbend, 1982), otorgando así la posibilidad que ellos/as elijan la forma que les parezca más conveniente para su proyecto de vida (Cortina, 1997).

Por tanto, la palabra de Juan construida desde la cotidianidad en su mundo de vida, es una invitación a cuestionar un mundo que se da por sentado, además de definir el acto educativo como un acontecer, una apertura (Derrida, 2001). Novedad que se alimentaría de los rumbos inesperados o insospechados que provienen de voces de tierras lejanas, periférica como cercanas, que no se escucha, o se hace desde la añoranza, el romanticismo y lo pintoresco. Sin embargo, en un diálogo real el otro/a es también un ser humano productor/a de saberes.

Un diálogo real entrega la oportunidad de sorprenderse de lo que el otro/a ofrece, brindando a la imaginación la posibilidad de proponer significados, flexibilidades, conexiones y transformaciones; en la certeza que la educación debe ser concebida como un modo de estar en y con el mundo, concebida como la vida misma, como alguna vez lo expresara Dewey (1995). En esta línea, el acontecer educativo debe intentar constituirse en una reflexión sobre la posibilidad de conversar con el/a otro/a en su pluralidad.

La apertura a las palabras de Juan desmonta la representación de la periferia con la personificación del retardo bárbaro, permitiendo, además, desmitificar la autorepresentación de la cultura hegemónica como sostén global de la razón y el progreso, representación que se hace presente en la educación actual (Lander, 2000; Castro-Gómez, 2007; Walsh, 2008).

Desde y con su habla se toma conciencia de las propias formas de saber-ser (que idealmente implican la noción de la unidad del organismo en su ambiente-flexible), que se van arraigando en la cultura, la cosmovisión y otros determinantes de la identidad, así como en los marcos de interpretación, comportamientos y actitud (Bowers, 2002; Bateson, 1991; Maturana y Varela, 2001). A través de su discurso nos acercamos a saberes milenarios que se han trasmitido de generación en generación, que se mueven a nivel local y que lamentablemente se mantienen ocultos por la vergüenza de ser menospreciados 
por carecer de carácter científico, pero que, sin embargo, sostienen una posición epistemológica re-creada por muchas culturas ecológicamente sustentables, que involucran relaciones profundamente diferentes a las que ofrece el conocimiento moderno, mismo que como lo indican Rengifo (2003), Morín (1999, 1988), Bowers (2002), entre otros/as, se caracteriza por la aprehensión y trasmisión de conocimientos construidos por otros/as.

Es ésta una propuesta que explicita la pertinencia y la necesidad del diálogo de saberes en la construcción de una educación contextual, que elimine formas ajenas de relacionarse y de convivir, posibilitando que las nuevas generaciones re-funden las condiciones de una vida buena y de un proyecto ecohumanizador que busque mejorar las condiciones del ser humano y del planeta (Gadotti, 2002), como una forma de asumir con responsabilidad su condición de seres que se construyen en su semejanza y diferencia, conteniendo al mismo tiempo a su familia, a su sociedad, a su cultura, a la humanidad, al medio ambiente y a la tierra (Illapa cit. en Mulino, 2006: 95). En este marco se buscaría una decolonización de la educación, del conocimiento y la re-fundación de una práctica otra (Walsh, 2007).

\section{PENSAMIENTO CRÍTICO DE LA CULTURA OCCIDENTAL MODERNA}

El pensamiento crítico de acuerdo a Dussel (2006), surge de nuestra situación de biculturalidad y, por tanto, de estar en la intersección que se forma entre nuestra cultura local y subordinada y la cultura moderna y hegemónica. Desde esta posición se tiene claro que la tecnología es el gran motor de la vida actual, al punto que se ha transformado casi en una prótesis del ser humano, naturalizándose la relación con el mundo mediada por ella. El aprendizaje en la educación formalizada se ha centrado en su uso, el cual ofrece la minimización del esfuerzo humano en las acciones que emprende. Esta búsqueda se viene llevando a cabo desde tiempos inmemoriales, ocurriendo incluso que algunos seres humanos han llegado al punto de menoscabar a otros/as con el fin de liberarse del peso del esfuerzo, por cuanto en algunos contextos la labor, el esfuerzo del propio cuerpo para la supervivencia que define la condición de ser humano, es menospreciada y evitada, lo que ha significado la expulsión de los/as que laboran al olvido y la explotación (Arendt, 1993).

Pareciera que, desde está metáfora arraigada en la cultura moderna, se ha llegado a definir una educación que se aleja de lo cotidiano, en especial en aquellos contextos subvalorados por la cultura hegemónica. Las percepciones holísticas que trae el/a niño/a de campo dentro de una cosmovisión en que todo es vivo, tienden a ser amputadas y reemplazadas en la escuela por la imagen de un mundo mecánico y manipulable, aprendiendo a segmentar y jugar con la realidad construida como si ésta fuera un objeto o un mecanismo cuyas piezas se pueden separar y juntar. Las nuevas generaciones de los entornos rurales aprenden que la verdad es lo representado. Juan nos dice al respecto: "ahora pregúntele a un niño dónde vive. No tiene ni idea, no tiene idea. Otro problema más allá, dígale a un niño súmame esto, a dónde van a sumar, si no saben. ¿Por qué saben? Por la calculadora". ${ }^{2}$

Juan cuestiona la preeminencia de los conocimientos por sobre los saberes que deberían re-crear las nuevas generaciones, por ello nos exige que se incorporen aprendizajes que no

2 Los fragmentos del discurso de Juan se presentarán en letra cursiva. 
estén separados de la vida misma. Él nos recuerda lo relevante del espacio, ya que éste definiría las relaciones y la identidad. El lugar es un atributo que en culturas campesinas cobra relevancia (Figueroa, 2005; Leff, 2002; 2006). La educación escolarizada (Illich, 1974) no re-produce el espacio como referente esencial de los bagajes culturales de los/ as campesinos, sino, por el contrario, lo coloniza por medio de los aparatos tecnológicos.

¿Dónde vivo? Es una interrogante que debe estar presente en la deconstrucción de un currículum que se ha orientado a la tecnología y a la separación de espacio/lugar y del vivir.

La tecnología ha provocado en palabras de Juan un no-aprendizaje: "La gente sabe menos y es responsable la persona que no tiene interés [...] Ya no, ya no, es tarde (para que los niños aprendan) ya no queda tiempo, se perdió todo, por la cuestión de la tele e internet. Que ahora van a pasar eso o esto otro, ahora solo creímos [sic] lo que sale en internet, pero ¿quién escribe eso?La pregunta que hago es eso, quién escribe eso. Otra gente. Y quién es más tonto, ¿uno o el que escribe? Uno, porque uno cree las cosas que otro escribe". Esto habría provocado que las nuevas generaciones estén adormecidas por verdades a medias, construidas por las elites hegemónicas (Chomsky, 2001).

Apreciamos que un discurso ajeno tiñe todas las formas de vida. Un discurso que contiene valores eurocéntricos y una normatividad que ha provocado la inercia, la apatía y el olvido de saberes, "la gente sabe menos". Los saberes han sido colonizados por el conocimiento científico y la tecnología, por la globalización, donde los/as del centro escriben la palabra y los/as de la periferia sólo la leen, es decir, se ha colonizado la vida por el informacionalismo (Castell, 2002). En la escuela no se vive, la vida está en suspenso, ya que los seres humanos están más preocupados por consumir información, información que adopta un carácter universal y cuyos creadores son omnipresentes, fluidos, sujetos a un espacio donde el ser tecnologizado sintoniza con una vida líquida (Bauman, 2003; 2005). Juan nos alerta sobre la gran narrativa moderna: la tecnología; que habla de un otro/a ausente; graficando la idea que algunos seres particulares se imponen sobre otros/as con tal efectividad, que éstos asumen pasivamente la desaparición de sus propias formas, como resultado del no-diálogo.

Asimismo, él nos entrega su perspectiva desde el hacer, desde lo necesario, una mirada desde el sostenimiento de una vida, posibilitándolo a denunciar: "la gente de Santiago que se cree porque tienen un televisor en cada pieza, tienen microonda; tanta cuestión de qué les sirve si están hasta aquí con las letras (deudas) pensando cómo pagar una u otra. Piden un préstamo aquí, allá para pagar acá y así se van. Yo gracias a Dios que aún nunca he sacado nada a letras."

Desde su perspectiva, todas las cosas y las relaciones se ven desde otra óptica, sobre todo la definición de qué es lo que constituye una buena vida, una vida tranquila, una vida que no se vaya en preocupaciones provocadas por la forma de satisfacer deseos que cada día son mayores y que sólo responde a la idea de tener más, "tienen un televisor en cada pieza", un estilo de vida marcado por el consumismo.

Para él la posibilidad de contar con tierra, animales y leña entregan al campesino/a la tranquilidad de una vida que podría vivirse. Si bien el dinero aparece como importante en su relato, privilegia los recursos naturales y el producto del esfuerzo, situación que percibimos cuando él recuerda su paso por los fundos como inquilino: "va a ganar usted fuera del sueldo que le daban unos 200 peso en esos años, le daban media cuadra de tierra en el potrero, mas la casa que tenía una media cuadra más de tierra, cuatro carretas de 
leña, mas talaje de cuatro vacas en el potrero". En la actualidad los/as campesinos/as se han quedado sin terrenos para el cultivo, empobrecidos/as. y las grandes extensiones de tierra han sido destinadas a monocultivos que ecológicamente representan una amenaza, además de una mala inversión. A pesar que en Chile se realizó un proceso de reforma agraria (trasferencias de derechos de propiedad de la tierra) no se llevo a cabo ningún cambio importante en la estructura de la tenencia de la tierra en el país (Bengoa, 2003). Solamente se originó una nueva subalternización del campesinado al mercado del trabajo. En términos de Arendt (1993) la labor del campesinado se convirtió en un producto que se tranza en el mercado, por lo cual sufre la alienación al no constituir una vida activa.

En sus palabras podemos deconstruir lo inapropiado de los conceptos de pobreza, riqueza y buena vida. Se infiere que, para él, el control de los medios de subsistencia: una vaca, tierra, leña y cierto ingreso monetario, son lo importante. Él privilegia y añora la economía agraria de antaño, pues le brindaba más posibilidades de subsistir con independencia, le daba orgullo, dignidad y sentido de igualdad. "Eran mejores las condicione $(s)$ antes, ahora ¿quién tiene una vaca amarrada? La vida antigua nada que ver con la vida de ahora. No hay nada en la actualidad". Él añora otra concepción de economía, una que contenga todo lo necesario para producir y mantener la vida en este planeta. Una concepción que comparten los proyectos que auspicia el GRAIN ${ }^{3}$ y el Movimiento campesino sin tierra (MST). Destaca en estos proyectos la idea de romper con el valor supremo de la propiedad privada, declarando que la tierra es de quien la trabaja, subordinada a los valores de la vida, la colaboración y el trabajo (Harnecker, 2002).

Por otra parte, menciona: "Aquí mismo... las Lomas del águila, más de 400 casas, que personas llegan aquí?... que médicos de Santiago, que milicos (militares), que carabineros, gente de afuera que ha llegado. Si por eso ya no va quedando en que sembrar y las mayoría de las cosas... en vez de hacer las cosas mejor, fueron peor, traen todo de afuera, entonces lo de aquí no vale nada." Él nos alerta sobre estos nuevos procesos que se están instalando en las zonas rurales, la llamada rururbanización. Juan observa con resignación e impotencia como las tierras de cultivo son ahora soporte físico de actividades residenciales y de ocio (Binimiles, 2000), concretando la conquista del espacio rural por parte de los habitantes de la ciudad. Parece ser que la ciudad se ensancha y da lugar a un cambio en las condiciones de contacto con el campo; en otras palabras, la urbanización aparece como la única forma de organización en las distintas sociedades, apareciendo la educación moderna formal como su mayor canalizadora.

Frente a todas estas deconstrucciones, Juan adopta una actitud pesimista, él dice " $\mathrm{Ya}$ no es tiempo, ya es muy tarde, ahora mismo ya no es tiempo. Yo le explico altiro (enseguida) porque no es tiempo, porque quién tiene la culpa: los padres y la madre, porque de ahí para arriba partió la cuestión. El niño está ahí, mira le dice la mamá al papá, pásale plata porque el niño va a la Disco. Oye y pásale unas 10 o 20 lucas (pesos), no le vaí a pasar unas 5 lucas. Entonces ¿quién está aumentando los vicios? Los dos en la casa". Estas palabras nos hacen reflexionar que la deconstrucción no es un trabajo fácil, pues significa combatir con las expresiones tecnocráticas y neoliberales hegemónicas de hoy, descritas como naturales, como tendencias espontáneas del desarrollo de

3 Organización internacional sin fines de lucro que trabaja apoyando a campesinos/as y agricultores/as en pequeña escala y a movimientos sociales en sus luchas por lograr sistemas alimentarios basados en la biodiversidad y controlados comunitariamente. Revisar http://www.grain.org/principal/ 
la sociedad, de las relaciones sociales y de las relaciones con el medio ambiente. Por lo tanto, apreciamos que se han colonizado los modelos de crianza que, al no ser construidos en las mismas comunidades, se polarizan, pierden el sentido con que fueron pensados, un ejemplo de esto lo constituyen los derechos del niño en relación a la recreación, al ocio, que llevados a un extremo han devenido en un no re-producir las pautas que la familia campesina requeriría para resistir a la colonización y a su desaparición como cultura.

Juan interpela a la familia. Pero, ¿qué pueden hacer los/as padres/madres en una sociedad escolarizada? ¿Cómo pueden los padres, qué ya no tienen a cargo la formación ética de sus hijos/as revertir esta situación? (Illich, 1974). Por otra parte, ¿Qué padres/ madres, aquellos/as a los que se les ha negado su participación en la construcción de un curriculum? ¿Cómo podrían participar aquellos/as padres/madres que han sido deslegitimados/as y/o silenciados/as en el sistema escolar porque no son profesionales? Aquellos padres y madres campesinos/as que no valoran su forma de vida, pues siempre han querido ser otros, salir afuera.(Contreras \& Ramírez, 2008, 2009).

En palabras de Illich

la escuela se apropia del dinero, de los hombres y de la buena voluntad disponible para educación y fuera de eso desalienta a otras instituciones respecto al asumir tareas educativas. El trabajo, el tiempo libre, la política, la vida ciudadana e incluso la vida familiar, dependen de las escuelas, en lo concerniente a los hábitos y conocimientos que presuponen, en vez de convertirse ellos mismos en los medios de educación (1974: 19).

Ciertamente nos referimos a una escuela que ha desestimado el diálogo con la comunidad, que no se ha dejado criar por ella, apropiándose a su vez del rol de crianza y negando la circularidad del proceso tal como lo entiende la gente de campo (Rengifo, 2003).

Juan comenta enérgicamente " $Y$ si quiere plata (dinero)... trabaje, aprenda a trabajar igual como uno cuando era chico, por eso yo salí a trabajar a los 7 años, de ahí jamás le pedí plata a mis padres, con lo que yo ganaba me vestía y le daba plata a mi madre para que comprará las cosas". Invitándonos a una deconstrucción del concepto de trabajo, un trabajo definido como colaboración y participación en las actividades de subsistencia de la economía familiar. Por cuanto la labor en la condición de vida humana sería un factor de liberación y no una obligación perversa como se piensa en la cultura occidental (Arendt, 1993). El trabajo es crianza, es aprendizaje, en él se vive y, por tanto, se sabe (Rengifo, 2003). Juan nos brinda la oportunidad de recordar el valor social del trabajo, por medio del cual se da el acto educativo, posibilitando así una participación efectiva.

En esta perspectiva, Illich comenta: "si el mayor fruto del trabajo del hombre debiera ser la educación que se deriva de éste y la oportunidad que el trabajo le da para iniciar la educación de otros, entonces la alienación de la sociedad moderna en un sentido pedagógico es aún peor que su alienación económica" (Illich, 1974: 38).

La escuela aún no conversa, por tanto, no se plantea preguntas ni respuestas a las siguientes interrogantes: ¿Cómo colaboran en sus hogares los/as niños/as campesinos/as sí ocupan la mayor parte de su tiempo en la escuela y en las labores escolares? ¿Cómo participan de la cosecha si ya se ha iniciado el periodo escolar y deben asistir a clases? ¿Qué hacer al respecto?

Interrogantes que sólo tienen sentido si la educación es definida como la vida misma (Dewey, 1995) y por tanto exige vivir, es decir, aprender, sentir, saborear, etc.: "¿aprender o no? había que aprender, había que aprender. Ahora ya no, ahora ya no, que lo que pasa es: toma anda a comprarte una bolsita de papa fritas. Antes se hacían en las casa, 
todo se hacía en la casa." El desafío está claro: aprender a vivir (que implica el hacer, saber, sentir y ser: una unidad), sin embargo, la escuela olvidó este mandato, por cuanto en ella se adormecen las vidas sobre edificaciones de un mundo virtual, construido en imágenes y representaciones, donde existe una mente ordenadora (Bateson, 1991).

La educación formal, tal como está planteada, constituiría un obstáculo para la práctica de la ciudadanía, entendida como presencia en el espacio público con otros/ as para la generación del mundo de vida (Cortina, 1997; Arendt, 1993). Consideramos que la educación en el campo no es de campo, puesto que no cría ni es criada por la comunidad, debilitando los procesos de construcción de la identidad personal y colectiva: "Porque es un deber del campesino que se críe en el campo, que tiene que gustarle la vida del campo, es un ritmo que no lo [es] para nadie". Nos referimos a una identidad que corresponda a la totalidad en su conjunto, que es estructurada y, a la vez, estructurante. Cada uno es uno/a y es un todo (Illapa cit. en Mulillo, 2006: 101). Un principio que da sentido y existencia a la interculturalidad.

\section{PRODUCCIÓN Y REPRODUCCIÓN DE SABERES}

Una condición para aprender, es vivir; vivir con una apertura sensitiva, emocional y afectiva hacia el habla, los gestos, los olores, los movimientos de los seres naturales y sagrados que pueblan la realidad próxima. Por tanto, la educación en estos contextos debe dialogar con la experiencia. Juan nos dice: "Sabe que la vida es así, para poder pagar la crianza de los padres hay que criar, para pagar la crianza, si no se paga la crianza no se sabe cómo lo criaron a uno."

En palabras de Rengifo, crianza: "es un verbo que connota mutualidad y amparo; al criar, lo criado te cría. Si todos son criadores, al mismo tiempo todos somos criados, la capacidad de criar es indesligable de la sensibilidad de dejarse criar" (Rengifo, 2009:56). Desde esta perspectiva, Rengifo privilegia el concepto de crianza para referirse a la actividad educativa y releyendo las palabras de Juan todo cobra sentido, ya que en ellas se percibe la responsabilidad y la interrelación entre las generaciones, vislumbrándose una ética que limita la libertad de acción, pero que tiende a preservar la integridad, estabilidad y belleza de la comunidad biótica. Una heteronomía que delega a la autonomía a un papel secundario, en pos de una verdadera ética de la alteridad (Levinas, 1991; Bárcena y Mélich, 2000).

Juan nos habla de "cuidarlos, tenerlos", una obligación que es inherente a todo ser que es parte de una unidad y, por lo tanto, de una totalidad. Es así como se asocia el saber con el hacer. Al comentar quién les enseñó a las nuevas generaciones de su familia, él dice "uno, conmigo trabajaron [...] Una persona que sea bien organizada, que tome desde chico su tranco (ritmo), igual que los cabros (niños) que yo crié, tomaron el tranco que llevaba yo, conmigo trabajaban, yo los lleve altiro (enseguida) a trabajar." En este párrafo destacan algunas ideas: la primera, la noción de un saber contextual "Tome desde chico su tranco, igual que los cabros que yo crié". En segundo lugar, se aprecia la idea que desde niño/a se vive, no se prepara para la vida, se está haciendo en un vivir que se construye junto a sus referentes identitarios. En tercer lugar, este "tomar su propio tranco" hace referencia a un vivir en la semejanza y en la diferencia, es decir, 
en la pluralidad de la condición humana. Por último, la vida como diversidad y contexto no acude a verdades universales favoreciendo la heterogeneidad.

En este marco, desde sus recuerdos (formas del saber) Juan relata: "Antes las escuelas enseñaban, las escuelas rurales tenían un sitio, así ahí nos enseñaban, el director de la escuela nos enseñaba a limpiar, a plantar, a todo esto, pero ahora, ¿adónde la escuela enseña alguna cosa? Le deberían enseñarle todo para que las personas aprendan, que sepan qué es una cosa y no sentarse con las manos mirando para adelante con la calculadora a un lado y al otro la pantalla de internet. Sí po'h, si para estudiar el niño tiene que aprender, no esa cuestión que mandan ahora, 4 ó 5 preguntas, van a internet, después, ¿cuándo van a hacer las cosas?” En su opinión, antes las escuelas conversaban con el saber y el aprendizaje se daba en un currículum contextual, pero en la actualidad los/ as docentes no han podido identificar los aspectos problemáticos de la cultura dominante: la tecnología, la centralidad del discurso, la copia de información, etc. Juan se pregunta (y nosotros también): ¿cómo van a aprender las nuevas generaciones en este modelo? Un modelo donde el saber está relegado a un segundo lugar, constituyendo un problema que los/as proponentes del aprendizaje mediado por los ordenadores continúa ignorando.

En este sentido, Juan manifiesta que no le interesa demasiado el hecho en sí ni su explicación, sino más bien cómo éste se vive. Por tanto, la trasmisión de un saber es fuertemente vivencial, todo pasaría por el matiz de la praxis. El saber estaría conectado con el hacer, siendo uno y lo mismo: "Tendría que aprender de todo el niño... sobre todo el niño de campo, en primer lugar cocinar, en segundo lugar arreglar, pegarse sus botones, su ropa, cocer, hacer cualquier cosa. Qué es lo que pasa, que es la mamá la que tiene que hacerlo todo o una hermana hacerlo todo. No po, nosotros no, a nosotros no nos enseñaron así. Sí sé nos cortaba un botón, mi madre decía: péguelo. [...] le enseñaron a uno, nos enseñaron a vivir."

En efecto, los saberes se recrean en las actividades humanas básicas que han sido ignoradas en los currículos, que refuerzan el conocimiento descontextualizado y los valores asociados con una cultura orientada hacia el consumismo. El aprendizaje al que se refiere Juan es él de lo cotidiano, él del mundo de la vida del que habla Habermas (1997). Esto no significa que Juan o las comunidades campesinas no deseen acceder al conocimiento moderno para ampliar sus oportunidades, lo que demandan es una conversación entre la escuela y la comunidad (Rengifo, 2003). Desde la perspectiva Arendtiana es dialogar con la no-mundaneidad lo que los/as campesinos/as realizan.

la única actividad que corresponde estrictamente a la experiencia de no-mundaneidad o, mejor dicho, a la pérdida del mundo tal como ocurre bajo el dolor [...] donde el cuerpo humano, a pesar de su actividad, vuelve sobre sí mismo, se concentra sólo en estar vivo, y queda apresado en su metabolismo con la naturaleza sin trascender o liberarse del repetido ciclo de su propio funcionamiento (Arendt, 1993:124).

Creemos que es desde ahí que se debe re-fundar la educación intercultural en contextos rurales. Parece importante recordar que antes existían otras instituciones que ejercían la acción educativa, la familia rural era capaz de entregar los saberes que se necesitaban para vivir. Juan nos relata "Cuando vinimos, a los 10, nosotros ya sabíamos leer, leer, sumar, sabíamos restar, multiplicar, dividir. Mi madre nos enseñaba y a todos en la casa, sí a todos. Hasta mi hermana que era mucho más chica y el otro hermano, 
todos sabíamos leer en la casa cuando veníamos a la escuela." Instituciones que en una sociedad escolarizada pierden su sentido (Illich, 1974).

Esta forma de aprender y los saberes que se reprodujeron entregaron a Juan el valor supremo de su identidad de campesino, otorgándole seguridad, independencia y felicidad. En otras palabras, él es un hombre empoderado. "Me siento feliz haciéndolo así, nadie tiene que abrirme los ojos y decirme: pucha, haga esto o lo otro, porque no está bien hecho lo que está haciendo. Hoy en día ya no, porque no, porque hoy día el niño es tan despierto ahora dicen... ¿despierto por qué? Por la televisión, despierto para fumar pito [marihuana], pero no para vivir".

Se evidencia que el gran impulso de la educación hoy en día es la creciente incorporación de áreas del currículo mediadas por el ordenador, lo cual significa comunicación y pensamiento basados en la palabra impresa. Un aprendizaje que no faculta para construir identidad y/o autonomía, pero sobre todo responsabilidad con la propia vida. "El conocimiento más audaz y lejano no nos pone en comunión con lo verdaderamente otro; no reemplaza a la socialidad; es todavía y siempre una soledad" (Levinas, 1991: 58). Juan se refiere a la confusión entre conocer y vivir, situación con la que coincidimos y por lo cual creemos al igual que Rengifo (2003) que se debe deconstruir el conocimiento como proceso de aprehensión y mostrar el saber como "una inmanencia, y que no existe ruptura ni aislamiento del ser en el saber; que, por otra parte, en la comunicación del saber, uno se halla al lado del otro, no confrontado a él" (Levinas 199: 55).

La relación abuelo/a-padre/madre-niño/niña sería uno de los pilares básicos de la recreación del saber. La existencia de este eslabón intergeneracional es el lazo en la relación de aprendizaje y crianza a que hacíamos mención anteriormente. Se aprende con y del otro/a en un contacto cara a cara. "Por mi padre, yo lo miraba, era muy buen compositor mi padre, él aprendió con mi abuelo. A mi padre lo miraba desde chico, lo miraba como componía. Decía yo: ¿costará mucho? Decía yo: ¿iré a aprender al final? A los 10 años me dijo: ¿por qué no me ayuda? Porque había un montón de gente, un pie hinchado. Me dijo: ¿por qué no me masajea este pie que está inflamado y no se puede componer? ¿Que me dijeron a mí? Aquí está la mía, para aprender... y empecé a componer."

Juan da testimonio de un principio básico: la memoria, con ella se advierte que la gente de campo tiene historia, sabiduría y saberes. Él estuvo inmerso desde muy pequeño en un saber que actualmente es exclusivo de las disciplinas de la salud. Un saber que se trasmite y recrea en el contacto, en el estar ahí con el otro/a, entregando alegría y enorgulleciendo al que lo posee. En su relato da muestras de un aprendizaje que se logra mediante una comunicación cara a cara, dentro de una comunidad real conformada por diferentes generaciones, en contraposición a la relación dentro de una comunidad de estudiantes que comparten básicamente la misma óptica en la instrucción que entregan los adultos (Dewey, 1995). Consideramos, por tanto, que estamos frente a un importante principio que la educación debería rescatar: revitalizar la comunicación entre las generaciones.

Ha de destacarse que éste y otros saberes no ocurren en soledad, se dan con otros/ as, pero también con las deidades: "Siento mi mano, yo digo una cosa, más que Dios no ayudo, si po, si para hacer cualquier trabajo primero le pido permiso al que manda, no hago las cosas solo, siempre le pido permiso a Dios y a los santos". El saber no es un atributo exclusivo del humano, sino también de las deidades. En suma, es una práctica donde dialogan las manos, el campesino y las deidades que responden a un proceso de 
sincretismo. Esta estructura se ve en todo y así se debe considerar sin eliminar mecánicamente lo occidental o el pensamiento mágico. En otras palabras, "existe una mente más amplia de la que la mente individual es solo un subsistema. La mente más amplia es comparable a Dios, y tal vez sea eso que algunas personas llaman Dios" (Bateson, 1991: 491).

Destacar, además, que la re-creación del saber de Juan es una gran ayuda para su comunidad, ya que promueve la autosuficiencia de la gente rural, quienes pueden solucionar problemas de salud sin acudir a la medicina tradicional y, por tanto, no incurrir en gastos. Además, está a la mano, cualquiera que lo desee puede obtenerlo, sin necesidad de exámenes, ni capital económico. En otras palabras, es un saber sustentable, propio y local, conformado por un pensamiento fronterizo que hace alusión a la diversidad de formas de pensamiento asentadas en las historias y experiencias de la colonialidad (Mignolo, 2007).

Entendemos que estos saberes son necesarios y pertinentes al contexto donde se desarrollan principalmente por su viabilidad. La sanación con el uso de hierbas es sustentable, pues es un recurso que se posee, es gratuito, se puede cultivar, conservar, etc. "La tierra en chile es la mejor, tenemos las mejores hierbas que en todos los países. Hay cualquier hierba para tomar. Mi padre salía para el cerro a buscar. Cuando iba al alto para el cerro a la gente que andaba conmigo, yo le decía: esta hierba sirve para esto y lo otro". Es un saber que está ahí y que contribuye a mejorar la calidad de vida. Pero, en la actualidad, esta práctica de resistencia se ha ido debilitando, pues ya no se incorpora en la vida de la gente, siendo reemplazada por la medicina moderna, aunque en muchas ocasiones de forma no del todo satisfactoria, según lo plantea Sieglin (2005) en un trabajo de investigación sobre medicina local campesina.

Por último, en el contexto de las crisis ambiental con su efecto colateral en la situación alimentaria y desde una mirada concordante con los planteamientos y demandas del enfoque territorial, desarrollo local y desarrollo sustentable, se propone una producción con eficacia energética (relacionada con la noción de energía endosomática: en torno al proceso de fotosíntesis, los ciclos, la proximidad, el territorio y la diversidad, en contraposición a la energía exosomática, vinculada a la energía del petróleo, energía nuclear, etc.). Propuesta que se evalúa como viable por constituir un saber que aún conservan algunos campesinos. Juan nos revela que aún se re-crean saberes para cultivar de manera sustentable y ecológica la tierra, "lo que siembro en la casa aquí, yo, es natural no tiene ninguna cosa, nada aquí y es distinto el gusto, el sabor, el color es muy distinto la misma sandía. La sandía es rica porque es dulce, porque no tiene ninguna cosa, nada, es delgada de cáscara. Uno siembra a la antigua".

En las zonas rurales sus habitantes cuentan con pequeños terrenos, existiendo la posibilidad de realizar cultivos ecológicos, sin embargo, esta práctica se ha ido perdiendo, ya que resultan tentadoras las ventajas en términos de velocidad en el crecimiento que ofrece el cultivo químico. Al irse perdiendo esta práctica se ha perdido también la trasmisión de esos saberes a las nuevas generaciones.

\section{CONCLUSIONES}

El saber/vivir de Juan sustenta un acto educativo a través de conexiones multidimensionales en la cotidianidad, en la labor, en la curación, en la imbricación con el ambiente, en la crianza de y con las nuevas generaciones. Un acto educativo que demanda diálogo, 
aprendizaje para vivir y que, por lo tanto, se sustenta en el saber como vivencia, para hacer eco de sus formas particulares de estar con y en el mundo, con y en sus deidades, con y en su cuerpo; con y en su corazón, tan propio de la gente de campo que no separa al ser humano de la naturaleza, al cuerpo de la mente, ni al hombre/mujer de las deidades (Rengifo, 2003; Bateson, 1991; Mazorco, 2006; entre otros/as).

Se desprende que el conocimiento representa una experiencia distinta del saber, generando una escuela rural descontextualizada, no pertinente, pues se funda en un discernimiento del mundo que se representa codificado, objetivo, universal, tecnologizado; que reproduce ideas y pensamientos de unos/as pocos/as ausentes y por tanto es independiente de tradiciones culturales locales y de la vida misma. Vida marcada por la labor del cuerpo y la interconexión con el medio ambiente.

No deseamos que el diálogo con Juan se limite sólo a reflexionar sobre los saberes y las demandas de las diversas colectividades que componen las sociedades, sino que esperamos que vaya más allá. Al respecto, Bowers plantea: “aprender a pensar y experimentar desde dentro de un nuevo marco conceptual o paradigma, en lugar de sólo ser capaz de pensar de ello, es uno de los desafíos más difíciles que tienen que enfrentar aquéllos que deseen generar una reforma fundamental"(2002:347), reforma que se hace evidentemente necesaria en la tarea educativa. Existen, sin duda, otras formas de saber distintas a las definidas por Juan, esta diversidad conlleva a admitir que existen tantos caminos para pensar e implementar la acción educativa, como formas de vivir la vida; tantas maneras, como puntos de partida sociales e interpretaciones individuales que de ella se construyan. En esta línea, nuestra intención ha sido visibilizar está forma cultural en particular, pues Juan se contiene a sí mismo, a su familia, a su comunidad, a su sociedad y a su entorno (Illapa cit.en Mulino 2006: 90).

Los saberes situados de Juan nos confirman la necesidad de re-fundación de la educación, en palabras de Capra "necesitamos una nueva manera de ver el mundo y una nueva manera de pensar -pensar en términos de relaciones, de conectividad, de contexto" (cit. en Bowers, 2002: 348). Es decir, deberíamos dar cabida nuevamente a la crianza.

Crianza que revertiría una educación dominada por un modelo mecanicista; que acepta y privilegia el pensar como procesamiento de información, dando lugar a una educación para vivir, una educación interconectada en una red de relaciones, en la que todos los procesos vitales de subsistencia dependen unos de otros, en una comunidad en que estudiantes, docentes, padres/madres y naturaleza están interconectados, dando lugar a un aprendizaje sustentable que garantice la supervivencia de todas las especies a largo plazo; que privilegie una educación basada en un principio de ciclos ecológicos, es decir, de intercambio entre materia y energía en ciclos continuos, donde cada uno/a sea a la vez maestro y aprendiz, que contenga la función de flexibilidad y heterogeneidad y que dé cuenta de las constantes recreaciones del entorno, así como de su capacidad de ser diverso, es decir, presentar un alto grado de complejidad originado por un real diálogo de saberes (Bowers, 2002).

La producción y reproducción de saberes que Juan nos presenta se asemeja a lo que Wendell Berry denominó cultura saludable:

Un orden comunal de memoria, intuición, valor, trabajo, convivencia, reverencia, aspiración. Revela las necesidades humanas y los límites humanos. Aclara nuestros irrenunciables vínculos con la tierra y entre nosotros. Asegura que las necesarias restricciones se observen, que se haga el trabajo necesario y que se lo haga bien (cit. en Bowers, 2002: 354). 
Por tanto, la educación al ser interpelada, debe generar espacios de trabajo colaborativo tendientes a diseñar currículos y programas que reflejen estos intereses, preocupaciones y requisitos singulares. La estrategia participativa empodera a los/as agentes con la propiedad y la responsabilidad completa. La generación de estas estrategias supone un proceso de decolonización del saber, además de registrar producciones teóricas y prácticas autónomas para construir currículo, poniendo al otro/a dentro de un paradigma válido en su contexto.

El otro, la otra o Juan no deben ser relegados a un mero testimonio, ya que ellos/as producen saberes y por tanto identidades, formas culturales, formas de vida, deidades, relaciones, instituciones, creencias, que desde una perspectiva intercultural deben aparecer en el espacio público. Los/as habitantes de las zonas rurales, por su constante interacción con la naturaleza, han venido creando, recreando y transmitiendo de generación en generación su propia sabiduría, basada en un saber unificado, vivo, flexible, contextual y cotidiano. Estos saberes, que aún muchos de ellos/as poseen, les posibilitan el empoderamiento y una sensación de felicidad, misma a la que ellos aspiran para las nuevas generaciones; por tanto, las escuelas rurales deberían apoyarse en un aprendizaje automotivado, "eso es una cosa, una cosa que se hacía más por entretención más que nada", la idea es que esto proporcione nuevos vínculos con el mundo, con la comunidad y su sabiduría, para alejarnos un poco de la contaminada profesionalización de la actividad educativa.

En conclusión la educación rural que se desprende de las inquietudes de Juan, debería tener tres objetivos: proporcionar a todos aquellos que lo quieren el acceso a recursos disponibles en cualquier momento de sus vidas; dotar a todos los que quieran compartir lo que saben del poder de encontrar a quienes quieran aprender de ellos; y, finalmente, dar a todo aquel que quiera presentar al público un tema de debate la oportunidad de dar a conocer su argumento (Illich, 1974:101).

¿Qué nos queda entonces por hacer? Deberíamos investigar más a fondo los modos de re-creación del saber y su diálogo con el conocimiento; invitándonos a elaborar currículum propios y contextualizados, avanzando en una pedagogía propia de los sectores rurales, para que dejen de ser colonizados por un conocimiento que no legitima su singular forma de estar en y con el mundo. Por tanto, debemos implicarnos en la "crianza" para refundar la educación en los escenarios inmediatos, mediatos y cotidianos.

Para finalizar, no podemos dejar de mencionar que probablemente en el trascurso de este ensayo se han colado metáforas enraizadas en nuestra propia forma de enfrentar otros modos de vivir, otras cosmovisiones, contrapuestas al discurso que se deseaba dejar hablar. Creemos que se han filtrado formas mecanicistas de entender procesos; algunas visiones del cambio como algo lineal y progresivo, una visión del individuo como unidad social (la tendencia a destacar a Juan como autor) y, finalmente, se ha colado el antropocentrismo, al momento de comparar las relaciones humanas con la naturaleza (nuestro mundo, sin tierra, la tierra de otro, etc.). Sólo tenemos por excusa lo difícil que resulta ver con otra mirada y hablar con otra lengua.

\section{REFERENCIAS BIBLIOGRÁFICAS}

Arendt, H. (1993). La condición humana, España: Editorial Paidos.

Bárcena, F., \& Mélich, J. (2000). Enmanuel Levinas: educación y hospitalidad. En F. Bárcena, \& J. Mélich, La Educación como acontecimiento ético. Natalidad, narración y hospitalidad (pp. 125-148). Barcelona: Paidos. 
Bateson, G. (1991). Pasos hacía una ecología de la mente. Buenos Aires Argentina: Editorial Planeta. Bauman, Z. (2005). Los retos de la educación en la modernidad líquida. Barcelona: Editorial Gedisa. Bauman, Z. (2003). Modernidad líquida. México: Fondo de Cultura Económica.

Bengoa, J. (2003). 25 años de Estudios rurales. Sociologías, Año 5, n. 10, 36-98.

Bowers, C. (2002). Detrás de la apariencia. Hacia la descolonización de la educación. Lima: PRATEC.

Castells, M. (2002). La sociedad red. En M. Castells, A. Giddens, \& A. Touraine, Teorías para una nueva sociedad. España: Fundación Marcelino Botín-Sanz.

Castro-Gómez, S. (2007). Decolonizar la universidad. La hybris del punto cero y el diálogo de saberes. En S. Castro-Gómez, \& R. Grosfoguel (eds.), El giro decolonial. Reflexiones para una diversidad epistémica más allá del capitalismo global (pp. 79-91). Bogotá: Siglo del hombre.

Chomsky, N. (2001). La (des)educación, Barcelona: Editorial Crítica.

Contreras, S., \& Ramírez, M. (2009). La escuela rural desde la mirada de padres y madres. Paradigma, vol. 30, n. 1, 87-102.

Contreras, S., \& Ramírez, M. (2008) La escuela rural y la construcción identitaria. Boletín de Investigación Educacional, vol. 23, n. 2, 201-216.

Cortina, A. (1997). Ciudadanos del mundo. Hacia una teoría de la ciudadanía, Madrid: Editorial Alianza.

De Sousa Santos, B. (2003). Crítica de la razón indolente. Contra el desperdicio de la experiencia, Bilbao: Editorial DESCLEÉ.

Dewey, J. (1995). Democracía y educación. Madrid: Morata.

Dussel, E. (2006). Filosofía de la cultura y la liberación. Ensayos. México: Universidad Autónoma de México.

Feyerabend, P. (1982). La ciencia en una sociedad libre. Madrid: Editorial Siglo XXI.

Figueroa, V. (2005) América Latina: descomposición y persistencia de lo campesino. Revista Latinoamericana de Economía, vol. 36, n. 142, 27-50.

Gadotti, M. (2002). Pedagogía de la tierra. Madrid: Siglo XXI.

Guzmán, E. (2005). Resistencias, permanencia y cambio. Estrategias campesinas de vida en el poniente de Morelos. México: Ediciones Plaza y Valdés.

Habermas, J. (1997). La lógica de las ciencias sociales. Madrid: Editorial Tecnos.

Harnecker, M. (2002). Sin tierra. Construyendo movimiento social. Madrid: Siglo XXI.

Hopenhayn, M. (2009) La educación intercultural: entre la igualdad y la diferencia. Pensamiento Iberoamericano 4, 49-72.

Illich, I. (1974). La sociedad desescolarizada. Madrid: Editorial Barral.

Iñiguez, L. (2006). El análisis del discurso en las ciencias sociales: variedades, tradiciones y prácticas. En L. Iñiguez (ed.), Análisis de discurso. Manual para las ciencias sociales (pp. 89-128). Barcelona: Editorial UOC.

Kymlicka, W. (2003). Estados multiculturales y ciudadanos interculturales. En R. Zariquiey (Ed.), Actas del V Congreso latinoamericano de Educación intercultural bilingue. Realidad multilingue y desafío intercultural.Ciudadnía, política y educación (pp. 47-82), Perú.

Kymlicka, W. (1996). Ciudadanía multicultural. Barcelona: Paidos.

Lander, E. (2000). Ciencias sociales. Saberes coloniales y eurocéntrismo. En E. Lander, La colonialidad del saber: eurocentrismo y ciencias sociales. Perspectivas Latinoamericanas (pp. 8-25). Buenos Aires: CLACSO.

Larrosa, J. (2001). Dar la palabra. En J. Larrosa, En la experiencia de la lectura. Estudios sobre literatura y formación (pp. 653-672). México: Fondo de Cultura Económica.

Leff, E. (2006). Aventura de la epistemología ambiental. México: Editorial Siglo XXI.

Leff, E. (2002). La transición hacía el desarrollo sustentable: perspectivas de América Latina y el Caribe. México: Publicado por Instituto Nacional de Ecología.

Levinas, E. (1991). Ética e Infinito. España: Colección dirigida por Valeriano Bozal. 
Maturana, H., \& Varela, F. (1980). El árbol del conocimiento. Bases biológicas del entendimiento humano, Madrid: Editorial Debate.

Mazorco, G. (2006). Bases epistemológicas de la intraculturalidad-interculturalidad. En F. Delgado, \& J. C. Mariscal, Educación intra e intercultural. Alternativas a la Reforma Educativa Neocolonizadora (pp. 73-80). Bolivia: AGRUCO-COMPAS.

Mignolo, W. (2007). El pensamiento decolonial: desprendimientoy apertura. En S. Castro-Gómez, \& R. Grosfoguel (eds.), El giro decolonial. Reflexiones para una diversidad epistémica más allá del capitalismo global (pp. 10-45). Bogotá: Siglo del hombre.

Mignolo, W. (2003). Historias locales/diseños globales. Colonialidad, conocimientos subalternos y pensamiento fronterizo. Madrid: Ediciones AKAL.

Morín, E. (1999). Los siete saberes necesarios para la educación del futuro. Colombia: UNESCO, Editorial Cooperativa del Magisterio.

Morín, E. (1988). El método. El conocimiento del conocimiento. Madrid: Editorial Cátedra.

Mulino, A. (2006). Algunas reflexiones sobre el conocimiento científico y la intraculturalidadinterculturalidad. En F. Delgado, \& J. C. Mariscal (eds.), Alternativas a la Reforma Educativa Neocolonizadora (pp. 81-96). Bolivia: AGRUCO-COMPAS.

Rengifo, G. (2009) La cultura educativa de la comunidad. Cosmovisión y producción de conocimientos en el medio andino-amazónico. Revista de Educación y Cultura, 72, 54-58.

Rengifo, G. (2003). La enseñanza de estar contento. Educación y afirmación cultural andina, Lima: PRATEC.

Sieglin, V. (2004). Modernización rural y devastación de la cultura tradicional campesina, México: Ediciones Plaza y Valdés.

Walsh, C. (2008). Interculturalidad, plurinacionalidad y decolonialidad: insurgencias políticoepistémicas de refundar el Estado. Tabula Rasa, 131-152.

Walsh, C. (2007). Interculturalidad y colonialidad del poder. Un pensamiento y posicionamiento "otro" desde la diferencia colonial. En S. Castro-Gómez, \& R. Grosfoguel (eds.), El giro decolonial. Reflexiones para una diversidad epistémica más allá del capitalismo global (pp. 47-61). Bogotá: Siglo del hombre.

Yampara, S. (2006). Cosmovisión, Uruq-Pacha, desarrollo y/o Qamaña Andino. En F. Delgado, \& J. C. Mariscal (eds.), Educación intra e intercultural. Alternativas a la Reforma Educativa Neocolonizadora (pp. 23-36). Bolivia: AGRUCO-COMPAS. 

Las colaboraciones, suscripciones y correspondencia deben ser dirigidas a la Dirección de la revista: Oficina de Publicaciones, Facultad de Filosofía y Humanidades, Universidad Austral de Chile, Fono/Fax: 5663 221275, Isla Teja s/n, Valdivia, Chile. E-mail: eped@uach.cl

Las suscripciones incluyen los gastos de envío:

Chile: cheque o vale vista por \$10.000. Otros países: US\$ 15 .

El canje debe ser enviado a Biblioteca Central, Universidad Austral de Chile, Correo 2, Valdivia 

Oficina de Publicaciones, Facultad de Filosofía y Humanidades, Universidad Austral de Chile www.humanidades.uach.cl 
